\section{JURNAL EKONOMI EFEKTIF}

ISSN : $2622-8882$, E-ISSN : 2622-9935

Jurnal Ekonomi Efektif, Vol. 2, No. 3, April 2020 @Prodi Manajemen Fakultas Ekonomi Universitas Pamulang

\title{
PENGARUH PELATIHAN DAN MOTIVASI TERHADAP KINERJA PEGAWAI PADA SEKRETARIAT DINAS PERHUBUNGAN PROVINSI DKI JAKARTA
}

\author{
N. Lilis Suryani ${ }^{*}$, Lili Sularmi², Muhammad Abdul Rajak ${ }^{3}$ \\ Universitas Pamulang \\ dosen00437@unpam.ac.id*
}

\begin{abstract}
ABSTRAK
Penelitian ini bertujuan untuk mengetahui pengaruh Pelatihan, motivasi dan kompetensi terhadap kinerja pegawai pada Sekretariat Dinas Perhubungan Provinsi DKI Jakarta. Metode yang digunakan adalah explanatory research dengan teknik analisis menggunakan analisis statistik dengan pengujian regresi, korelasi, determinasi dan uji hipotesis. Hasil penelitian ini Pelatihan berpengaruh signifikan terhadap kinerja pegawai sebesar 42,3\%, uji hipotesis diperoleh $\mathrm{t}$ hitung $>\mathrm{t}$ tabel atau $(7,562>1,991)$. Motivasi berpengaruh signifikan terhadap kinerja pegawai sebesar 52,6\%, uji hipotesis diperoleh $t$ hitung $>t$ tabel atau $(9,311>1,991)$. Pelatihan dan motivasi secara simultan berpengaruh signifikan terhadap kinerja pegawai dengan persamaan regresi $\mathrm{Y}=9,685+0,291 \mathrm{X} 1+0,466 \mathrm{X} 2$ dan kontribusi pengaruh sebesar $59,4 \%$, uji hipotesis diperoleh $\mathrm{F}$ hitung $>\mathrm{F}$ tabel atau $(56,216>3,970)$.
\end{abstract}

Kata Kunci: Pelatihan, Motivasi, Kinerja Pegawai.

\begin{abstract}
This study aims to determine the effect of training, motivation and competence on employee performance at the Jakarta Transportation Agency Secretariat. The method used is explanatory research with analysis techniques using statistical analysis with regression testing, correlation, determination and hypothesis testing. The results of this study training has a significant effect on employee performance by $42.3 \%$, hypothesis testing is obtained t count> t table or (7.562> 1.991). Motivation has a significant effect on employee performance by $52.6 \%$, hypothesis testing is obtained $t$ count $>t$ table or $(9.311>1.991)$. Training and motivation simultaneously have a significant effect on employee performance with the regression equation $Y=9.685+0.291 X 1+0.466 X 2$ and the contribution of the effect is $59.4 \%$, the hypothesis test obtained $F$ count $>F$ table or $(56.216>3,970)$.
\end{abstract}

Keywords: Training, Motivation, Employee Performance. 


\section{PENDAHULUAN}

\section{A. Latar Belakang Masalah}

Mulai tahun 1990-an muncul paradigma baru yang sering disebut New Public Management/ NPM (Hood, 1991). Walaupun juga disebut dengan nama lain misalnya Postbureaucratic Paradigm (Barzeley, 1992), dan Reinventing Government (Osborne dan Gaebler, 1992), tetapi secara umum disebut NPM karena berangkat dari gagasan Christopher Hood sebagai awal mula paradigma alternatif. Paradigma tersebut muncul akibat adanya kritikan keras yang ditujukan kepada organisasi sektor publik yang sering tidak produktif, tidak efisien, selalu rugi, rendah kualitas, miskin inovasi dan kreativitas. New Public Management berfokus pada manajemen sektor publik yang berorientasi pada kinerja, bukan berorientasi kebijakan. New Public Management pada awalnya lahir di negara-negara maju di Eropa dan Amerika. Namun, negara-negara berkembang juga sudah mulai menggunakan konsep ini, begitu juga dengan Indonesia.

Sebagai negara yang juga turut ingin berbenah, Indonesia berusaha menerapkan paradigma NPM tersebut, meski ada sikap pesimis dari berbagai pihak mengenai kesanggupan penerapannya. Di Indonesia sendiri, pelaksanaan manajemen kinerja pada organisasi sektor publik sebenarnya sudah dimulai sejak tahun 1999 dengan dikeluarkannya Instruksi Presiden Nomor 7 Tahun 1999 tentang Akuntabilitas Kinerja Instansi Pemerintah. Penerapan New Public Management di

Indonesia dapat dilihat dari penerapan beberapa karakteristik-karakteristiknya di dalam praktek-praktek yang tengah di jalankan oleh instansi- instansi pemerintahan di Indonesia. Manajemen kinerja dapat didefinisikan sebagai daya upaya untuk meningkatkan kemampuan dan mendorong pegawai melalui berbagai cara agar bekerja dengan penuh semangat, efektif, efisien dan produktif, sesuai dengan proses kerja yang benar agar mencapai hasil kerja yang optimal.

Salah satu upaya untuk meningkatkan kemampuan pegawai adalah dengan cara memberikan pelatihan yang cukup. Menurut Simamora dalam Mustofa kamil (2010:4) mengartikan pelatihan sebagai serangkaian aktivitas yang dirancang untuk meningkatkan keahlian-keahlian, pengetahuan, pengalaman, ataupun perubahan sikap seorang individu.

Menurut Surya Dharma (2011:281) menyatakan bahwa pentingnya suatu pelatihan baik para manajer mengoperasikan manajemen kinerja secara efektif. Sebagian besar, di antara mereka yang terlibat secara tidak sadar telah mempelajari keahlian dalam menentukan sasaran, memberikan umpan balik, memberikan Coaching dan Conseling. Kedua belah pihak dalam proses manajemen kinerja juga memerlukan bimbingan dan pelatihan dalam menggunakan kompetensi, mempersiapkan kesepakatan dan rencana kerja, mempersiapkan diri untuk dan melaksanakan pertemuan evaluasi kinerja, penilaian dan pengisian formulir evaluasi.

Pelatihan memberi para pembelajar dalam meningkatkan pengetahuan dan ketrampilan yang dibutuhkan untuk pekerjaan mereka saat ini. Hal penting dalam sebuah peruasahaan adalah mensosialisasikan para karyawan ke dalam budaya peruasahaan agar mereka dapat menjadi karyawan dengan memiliki kinerja yang baik. Melalui pelatihan itu, karyawan terbantu mengerjakan pekerjaan yang ada, dapat meningkatkan keseluruhan karier karyawan, membantu mengembangkan tanggung jawab mereka dimasa yang akan datang serta meningkatkan kinerja karyawan.

Motivasi kerja PNS baik individu maupun organisasi menunjukkan kecenderungan penurunan. Hal ini terlihat dari pekerjaan, khususnya penyelesaian kegiatan penelitian dan pengembangan (litbang) kurang dapat diselesaikan dengan tepat waktu sesuai dengan perencanaan, baik secara individu maupun organisasi. Kecenderungan yang umum terjadi adalah sering kegiatan litbang yang dilakukan terpaksa dikerjakan "kejar tayang" karena 
mendekati batasan alokasi yang tersedia, sehingga dapat dimaklumi hasil litbang tersebut secara kualitas jauh dari sempurna.

Motivasi untuk melakukan litbang dengan mengembangkan inisiatif, inovasi dan kreatifitas dari personil maupun kelompok kerja (pokja) relatif masih rendah. Kalaupun pekerjaan/program kerja litbang itu selesai hanya sebagai sebuah pemenuhan kewajiban administrasi, kurang menyentuh kualitas hasil litbang seperti yang diharapkan.

Pegawai yang memiliki motivasi kerja yang tinggi umumnya lebih berhasil dalam tugas dan perkembangan kariernya dibandingkan pegawai yang kurang motivasi. Alasan tersebut diatas mendorong dan menginspirasi penulis untuk melakukan penelitian ini dengan memfokuskan pada "Pengaruh Pelatihan, Motivasi dan Kompetensi Terhadap Kinerja Pegawai Pada Sekretariat Dinas Perhubungan Provinsi DKI Jakarta”.

\section{Rumusan Masalah}

a. Adakah pengaruh Pelatihan terhadap kinerja pegawai pada Sekretariat Dinas Perhubungan Provinsi DKI Jakarta?.

b. Adakah pengaruh motivasi terhadap kinerja pegawai pada Sekretariat Dinas Perhubungan Provinsi DKI Jakarta?.

c. Adakah pengaruh Pelatihan dan motivasi terhadap kinerja pegawai pada Sekretariat Dinas Perhubungan Provinsi DKI Jakarta?.

\section{Tujuan Penelitian}

a. Untuk mengetahui pengaruh Pelatihan terhadap kinerja pegawai pada Sekretariat Dinas Perhubungan Provinsi DKI Jakarta.

b. Untuk mengetahui pengaruh motivasi terhadap kinerja pegawai pada Sekretariat Dinas Perhubungan Provinsi DKI Jakarta.

c. Untuk mengetahui pengaruh Pelatihan dan motivasi terhadap kinerja pegawai pada Sekretariat Dinas Perhubungan Provinsi DKI Jakarta.

\section{METODE PENELITIAN}

\section{Populasi}

Populasi dalam penelitian ini berjumlah 80 responden Sekretariat Dinas Perhubungan Provinsi DKI Jakarta

\section{Sampel}

Teknik pengambilan sampling dalam penelitian ini adalah samplel jenuh, dimana semua anggota populasi dijasikan sebagai sampel. Dengan demikian sampel dalam penelitian ini berjumlah 80 responden.

\section{Jenis Penelitian}

Jenis penelitian yang dipakai adalah asosiatif, dimana tujuannya adalah untuk mengetahui pengaruh antara variabel bebas terhadap variabel terikat baik parsial maupun simultan

\section{Metode Analisis Data}

Dalam menganalisis data digunakan uji instrumen, uji asumsi klasik, regresi, koefisien determinasi dan uji hipotesis

\section{HASIL PENELITIAN DAN PEMBAHASAN}

\section{Analisis Deskriptif}

Pada pengujian ini digunakan untuk mengetahui skor minimum dan maksimum, mean score dan standar deviasi dari masing-masing variabel. Adapun hasilnya sebagai berikut: 
Tabel 1. Hasil Analisis Descriptive Statistics

Descriptive Statistics

\begin{tabular}{|l|l|r|r|r|r|} 
& N & Minimum & Maximum & Mean & \multicolumn{1}{c|}{ Std. Deviation } \\
\hline Pelatihan (X1) & 80 & 28 & 46 & 38.50 & 3.955 \\
\hline Motivasi (X2) & 80 & 31 & 46 & 38.14 & 3.932 \\
\hline Kinerja Pegawai (Y) & 80 & 30 & 47 & 38.68 & 3.503 \\
\hline Valid N (listwise) & 80 & & & & \\
\hline
\end{tabular}

$\overline{\text { Pelatihan diperoleh varians minimum sebesar } 28 \text { dan varians maximum } 46}$ dengan mean score sebesar 3,85 dengan standar deviasi 3,955.

Motivasi diperoleh varians minimum sebesar 31 dan varians maximum 46 dengan mean score sebesar 3,81 dengan standar deviasi 3,932.

Kinerja pegawai diperoleh varians minimum sebesar 30 dan varians maximum 47 dengan mean score sebesar 3,86 dengan standar deviasi 3,503.

\section{Analisis Verifikatif.}

Pada analisis ini dimaksudkan untuk mengetahui pengaruh variabel independen terhadap variabel dependen. Adapun hasil pengujian sebagai berikut:

\section{a. Analisis Regresi Linier Sederhana dan Berganda}

Uji regresi ini dimaksudkan untuk mengetahui perubahan variabel dependen jika variabel independen mengalami perubahan. Adapun hasil pengujiannya sebagai berikut:

Tabel 2. Hasil Uji Regresi Linier Sederhana Variabel Pelatihan (X1)

\begin{tabular}{|c|c|c|c|c|c|c|}
\hline & & & fficients ${ }^{a}$ & & & \\
\hline & & $\begin{array}{r}\text { Unsta } \\
\text { Coe }\end{array}$ & $\begin{array}{l}\text { dardized } \\
\text { icients }\end{array}$ & $\begin{array}{l}\text { Standardized } \\
\text { Coefficients }\end{array}$ & & \\
\hline & & B & Std. Error & Beta & $t$ & Sig. \\
\hline 1 & (Constant) & 16.497 & 2.948 & & 5.596 & .000 \\
\hline & Pelatihan $(\mathrm{X} 1)$ & .576 & .076 & .650 & 7.562 & .000 \\
\hline
\end{tabular}

a. Dependent Variable: Kinerja Pegawai $(\mathrm{Y})$

Berdasarkan hasil pengujian pada tabel di atas, diperoleh persamaan regresi $\mathrm{Y}=$ $16,497+0,576 X 1$. Dari persamaan tersebut dijelaskan sebagai berikut:

1) Konstanta sebesar 16,497 diartikan jika Pelatihan tidak ada, sementara variabel lain konstan, maka telah terdapat nilai kinerja pegawai sebesar 16,497 point.

2) Koefisien regresi Pelatihan sebesar 0,576, angka ini positif artinya setiap ada peningkatan Pelatihan sebesar 0,576 maka kinerja pegawai juga akan mengalami peningkatan sebesar 0,576 point.

Tabel 3. Hasil Uji Regresi Linier Sederhana Variabel Motivasi (X2)

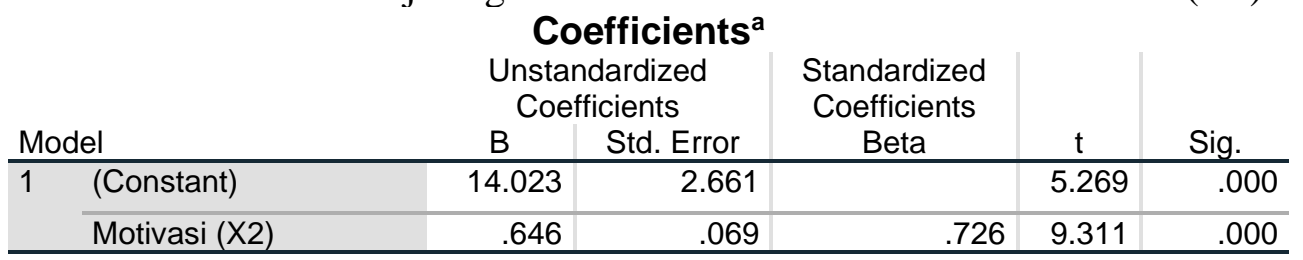

a. Dependent Variable: Kinerja Pegawai $(\mathrm{Y})$

Berdasarkan hasil pengujian pada tabel di atas, diperoleh persamaan regresi $\mathrm{Y}=$ $14,023+0,646 X 2$. Dari persamaan tersebut dijelaskan sebagai berikut:

1) Konstanta sebesar 14,023 diartikan jika motivasi tidak ada, sementara variabel lain konstan, maka telah terdapat nilai kinerja pegawai sebesar 14,023 point.

2) Koefisien regresi motivasi sebesar 0,646, angka ini positif artinya setiap ada peningkatan motivasi sebesar 0,646 maka kinerja pegawai juga akan mengalami peningkatan sebesar 0,646 point. 
Tabel 4. Hasil Uji Regresi Linier Berganda Coefficients $^{\mathrm{a}}$

\begin{tabular}{|c|c|c|c|c|c|c|}
\hline & & & efficients & & & \\
\hline & & $\begin{array}{r}\text { Unsta } \\
\text { Coe }\end{array}$ & $\begin{array}{l}\text { dardized } \\
\text { icients }\end{array}$ & $\begin{array}{l}\text { Standardized } \\
\text { Coefficients }\end{array}$ & & \\
\hline & & B & Std. Error & Beta & $\mathrm{t}$ & Sig. \\
\hline$\overline{1}$ & (Constant) & 9.685 & 2.764 & & 3.504 & .001 \\
\hline & Pelatihan (X1) & 291 & .082 & 328 & 3.565 & .001 \\
\hline & Motivasi (X2) & .466 & .082 & .524 & 5.683 & .000 \\
\hline
\end{tabular}

a. Dependent Variable: Kinerja Pegawai $(\mathrm{Y})$

Berdasarkan hasil pengujian pada tabel di atas, diperoleh persamaan regresi $\mathrm{Y}=$ $9,685+0,291 X 1+0,466$ X2. Dari persamaan tersebut dijelaskan sebagai berikut:

1) Konstanta sebesar 9,685 diartikan jika Pelatihan dan motivasi tidak ada, maka telah terdapat nilai kinerja pegawai sebesar 9,685 point.

2) Koefisien regresi Pelatihan sebesar 0,291, angka ini positif artinya setiap ada peningkatan Pelatihan sebesar 0,291 maka kinerja pegawai juga akan mengalami peningkatan sebesar 0,291 point.

3) Koefisien regresi motivasi sebesar 0,466, angka ini positif artinya setiap ada peningkatan motivasi sebesar 0,466 maka kinerja pegawai juga akan mengalami peningkatan sebesar 0,466 point.

\section{b. Analisis Koefisien Korelasi}

Analisis koefisien korelasi dimaksudkan untuk mengetahui tingkt kekuatan hubungan dari variabel independen terhadap variabel dependen baik secara parsial maupun simultan. Adapun hasil pengujian sebagai berikut:

Tabel 5. Hasil Uji Koefisien Korelasi Pelatihan Terhadap Kinerja Pegawai.

\section{Correlations $^{\text {b }}$}

\begin{tabular}{llr|r} 
& & \multicolumn{2}{r}{$\begin{array}{r}\text { Kinerja Pegawai } \\
(Y)\end{array}$} \\
\hline Pelatihan (X1) & Pearson Correlation & Pelatihan (X1) & $.650^{* *}$ \\
\cline { 2 - 4 } & Sig. (2-tailed) & .000 \\
\hline Kinerja Pegawai (Y) & Pearson Correlation & $.650^{* *}$ & 1 \\
\cline { 2 - 4 } & Sig. (2-tailed) & .000 & \\
\hline
\end{tabular}

${ }^{\star *}$. Correlation is significant at the 0.01 level (2-tailed).

b. Listwise $\mathrm{N}=80$

Berdasarkan hasil pengujian diperoleh nilai korelasi sebesar 0,650 artinya Pelatihan memiliki hubungan yang kuat terhadap kinerja pegawai.

Tabel 6. Hasil Uji Koefisien Korelasi Motivasi Terhadap Kinerja Pegawai.

\section{Correlations $^{\mathrm{b}}$}

\begin{tabular}{llr|r} 
& & Kinerja Pegawai \\
& & Motivasi (X2) & \multicolumn{2}{c}{$(\mathrm{Y})$} \\
\hline Motivasi (X2) & Pearson Correlation & 1 & $.726^{* *}$ \\
\cline { 2 - 4 } & Sig. (2-tailed) & & .000 \\
\hline Kinerja Pegawai (Y) & Pearson Correlation & $.726^{* *}$ & 1 \\
\cline { 2 - 4 } & Sig. (2-tailed) & .000 & \\
\hline
\end{tabular}

**. Correlation is significant at the 0.01 level (2-tailed).

b. Listwise $\mathrm{N}=80$

Berdasarkan hasil pengujian diperoleh nilai korelasi sebesar 0,726 artinya motivasi memiliki hubungan yang kuat terhadap kinerja pegawai.

Tabel 7. Hasil Pengujian Koefisien Korelasi Pelatihan dan Motivasi secara simultan

Terhadap Kinerja Pegawai.

\section{Model Summary}

\begin{tabular}{ll|rr|r} 
Model & $\mathrm{R}$ & $\mathrm{R}$ Square & Adjusted R Square & Std. Error of the Estimate \\
\hline 1 & $.770^{\mathrm{a}}$ & .594 & .583 & 2.262 \\
\hline
\end{tabular}

a. Predictors: (Constant), Motivasi (X2), Pelatihan (X1) 
Berdasarkan hasil pengujian diperoleh nilai korelasi sebesar 0,770 artinya Pelatihan dan motivasi secara simultan memiliki hubungan yang kuat terhadap kinerja pegawai.

\section{c. Analisis Koefisien Determinasi}

Analisis koefisien determinasi dimaksudkan untuk mengetahui besarnya persentase pengaruh dari variabel independen terhadap variabel dependen baik secara parsial maupun simultan. Adapun hasil pengujian sebagai berikut:

Tabel 8. Hasil Uji Koefisien Determinasi Pelatihan Terhadap Kinerja Pegawai.

\section{Model Summary}

\begin{tabular}{lrr|rr|r} 
Model & $\mathrm{R}$ & R Square & $\begin{array}{c}\text { Adjusted R } \\
\text { Square }\end{array}$ & \multicolumn{2}{c}{$\begin{array}{c}\text { Std. Error of the } \\
\text { Estimate }\end{array}$} \\
\hline 1 & & $.650^{\mathrm{a}}$ & .423 & .416 & 2.678 \\
\hline
\end{tabular}

a. Predictors: (Constant), Pelatihan (X1)

Berdasarkan hasil pengujian diperoleh nilai determinasi sebesar 0,423 artinya Pelatihan memiliki kontribusi pengaruh sebesar 42,3\% terhadap kinerja pegawai.

Tabel 9. Hasil Uji Koefisien Determinasi Motivasi Terhadap Kinerja Pegawai.

Model Summary

\begin{tabular}{lrr|rr|r} 
Model & $\mathrm{R}$ & R Square & $\begin{array}{c}\text { Adjusted R } \\
\text { Square }\end{array}$ & \multicolumn{2}{c}{$\begin{array}{c}\text { Std. Error of the } \\
\text { Estimate }\end{array}$} \\
\hline 1 & $.726^{\mathrm{a}}$ & .526 & .520 & 2.426 \\
\hline
\end{tabular}

a. Predictors: (Constant), Motivasi (X2)

Berdasarkan hasil pengujian diperoleh nilai determinasi sebesar 0,526 artinya motivasi memiliki kontribusi pengaruh sebesar 52,6\% terhadap kinerja pegawai.

Tabel 10. Hasil Uji Koefisien Determinasi Pelatihan dan Motivasi Terhadap Kinerja Pegawai.

\begin{tabular}{|c|c|c|c|c|}
\hline \multirow[b]{2}{*}{ Model } & \multicolumn{3}{|c|}{ Model Summary } & \multirow[b]{2}{*}{ Std. Error of the Estimate } \\
\hline & $\mathrm{R}$ & R Square & Adjusted R Square & \\
\hline 1 & $.770^{\mathrm{a}}$ & .594 & .583 & 2.262 \\
\hline
\end{tabular}

Berdasarkan hasil pengujian diperoleh nilai determinasi sebesar 0,594 artinya Pelatihan dan motivasi secara simultan memiliki kontribusi pengaruh sebesar 59,4\% terhadap kinerja pegawai, sedangkan sisanya sebesar 40,6\% dipengaruhi faktor lain.

\section{d. Uji Hipotesis}

\section{Uji hipotesis Parsial (Uji t)}

Pengujian hipotesis dengan uji t digunakan untuk mengetahui hipotesis parsial mana yang diterima.

Hipotesis pertama: Terdapat pengaruh yang signifikan antara Pelatihan terhadap kinerja pegawai.

Tabel 11. Hasil Uji Hipotesis Pelatihan Terhadap Kinerja Pegawai.

\begin{tabular}{|c|c|c|c|c|c|c|}
\hline \multirow{2}{*}{\multicolumn{2}{|c|}{ Model }} & \multicolumn{2}{|c|}{$\begin{array}{l}\text { Unstandardized } \\
\text { Coefficients }\end{array}$} & \multirow{2}{*}{$\begin{array}{c}\text { Standardized } \\
\text { Coefficients } \\
\text { Beta }\end{array}$} & \multirow[b]{2}{*}{$t$} & \multirow[b]{2}{*}{ Sig. } \\
\hline & & $\mathrm{B}$ & Std. Error & & & \\
\hline 1 & (Constant) & 16.497 & 2.948 & & 5.596 & .000 \\
\hline & Pelatihan (X1) & .576 & .076 & .650 & 7.562 & .000 \\
\hline
\end{tabular}

a. Dependent Variable: Kinerja Pegawai $(\mathrm{Y})$

Berdasarkan hasil pengujian pada tabel di atas, diperoleh nilai t hitung $>\mathrm{t}$ tabel atau $(7,562>1,991)$, dengan demikian hipotesis pertama yang diajukan bahwa terdapat pengaruh yang signifikan atara Pelatihan terhadap kinerja pegawai diterima. 
Tabel 12. Hasil Uji Hipotesis Motivasi Terhadap Kinerja Pegawai.

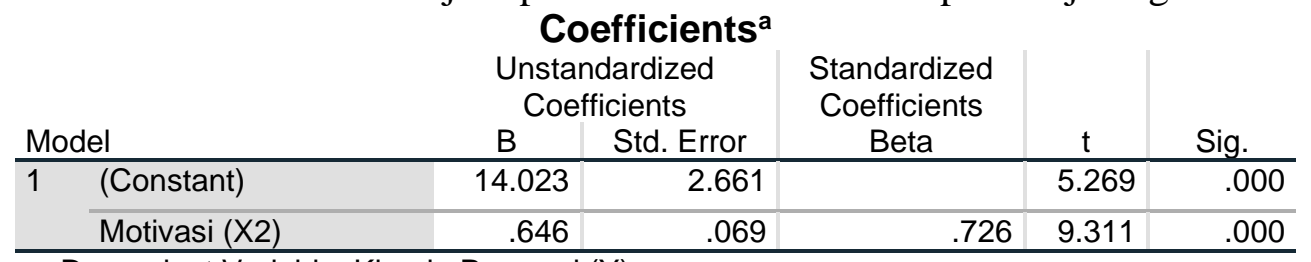

a. Dependent Variable: Kinerja Pegawai $(\mathrm{Y})$

Berdasarkan hasil pengujian pada tabel di atas, diperoleh nilai $\mathrm{t}$ hitung $>\mathrm{t}$ tabel atau $(9,311>1,991)$, dengan demikian hipotesis kedua yang diajukan bahwa terdapat pengaruh yang signifikan atara motivasi terhadap kinerja pegawai diterima.

\section{Uji Hipotesis Simultan (Uji F)}

Pengujian hipotesis dengan uji $\mathrm{F}$ digunakan untuk mengetahui hipotesis simultan yang mana yang diterima.

Hipotesis keempat Terdapat pengaruh yang signifikan antara Pelatihan, motivasi dan Kompetensiterhadap kinerja pegawai.

Tabel 13. Hasil Uji Hipotesis Pelatihan, Motivasi dan Kompetensi Terhadap Kinerja Pegawai.

\begin{tabular}{|c|c|c|c|c|c|c|}
\hline \multicolumn{7}{|c|}{ ANOVA $^{a}$} \\
\hline Model & & Sum of Squares & $\mathrm{df}$ & Mean Square & $\mathrm{F}$ & Sig. \\
\hline \multirow[t]{3}{*}{1} & Regression & 575.448 & 2 & 287.724 & 56.216 & $.000^{\mathrm{b}}$ \\
\hline & Residual & 394.102 & 77 & 5.118 & & \\
\hline & Total & 969.550 & 79 & & & \\
\hline
\end{tabular}

Berdasarkan hasil pengujian pada tabel di atas, diperoleh nilai $\mathrm{F}$ hitung $>\mathrm{F}$ tabel atau $(56,216>3,970)$, dengan demikian hipotesis ketiga yang diajukan bahwa terdapat pengaruh yang signifikan atara Pelatihan dan motivasi terhadap kinerja pegawai diterima.

\section{PEMBAHASAN HASIL PENELITIAN}

\section{Pengaruh Pelatihan Terhadap Kinerja Pegawai}

Pelatihan berpengaruh signifikan terhadap kinerja pegawai dengan diperoleh persamaan regresi $\mathrm{Y}=16,497+0,576 \mathrm{X} 1$, nilai korelasi sebesar 0,650 atau memiliki hubungan yang kuat dengan kontribusi pengaruh sebesar 42,3\%. Pengujian hipotesis diperoleh nilai $t$ hitung $>t$ tabel atau $(7,562>1,991)$. Dengan demikian hipotesis pertama yang diajukan bahwa terdapat berpengaruh signifikan antara Pelatihan terhadap kinerja pegawai diterima.

\section{Pengaruh Motivasi Terhadap Kinerja Pegawai}

Motivasi berpengaruh signifikan terhadap kinerja pegawai dengan diperoleh persamaan regresi $\mathrm{Y}=14,023+0,646 \mathrm{X} 2$, nilai korelasi sebesar 0,726 atau memiliki hubungan yang kuat dengan kontribusi pengaruh sebesar 52,6\%. Pengujian hipotesis diperoleh nilai thitung $>\mathrm{t}$ tabel atau $(9,311>1,991)$. Dengan demikian hipotesis kedua yang diajukan bahwa terdapat berpengaruh signifikan antara motivasi terhadap kinerja pegawai diterima.

\section{Pengaruh Pelatihan, Motivasi Dan Kompetensi Terhadap Kinerja Pegawai}

Pelatihan, motivasi dan Kompetensi berpengaruh signifikan terhadap kinerja pegawai dengan diperoleh persamaan regresi $\mathrm{Y}=9,685+0,291 \mathrm{X} 1+0,466 \mathrm{X} 2$, nilai korelasi sebesar 0,770 atau memiliki hubungan yang kuat dengan kontribusi pengaruh sebesar $59,4 \%$ sedangkan sisanya sebesar 40,6\% dipengaruhi faktor lain. Pengujian hipotesis diperoleh nilai $\mathrm{F}$ hitung $>\mathrm{F}$ tabel atau $(56,216>3,970)$. Dengan demikian hipotesis ketiga yang diajukan bahwa terdapat berpengaruh signifikan antara Pelatihan dan motivasi terhadap kinerja pegawai diterima. 


\section{PENUTUP}

\section{Kesimpulan}

a. Pelatihan berpengaruh signifikan terhadap kinerja pegawai dengan kontribusi pengaruh sebesar 42,3\%. Uji hipotesis diperoleh nilai t hitung > t tabel atau $(7,562>1,991)$.

b. Motivasi berpengaruh signifikan terhadap kinerja pegawai dengan kontribusi pengaruh sebesar 52,6\%. Uji hipotesis diperoleh nilai t hitung > t tabel atau $(9,311>1,991)$.

c. Pelatihan, motivasi dan Kompetensi berpengaruh signifikan terhadap kinerja pegawai dengan kontribusi pengaruh sebesar 59,4\% sedangkan sisanya sebesar 40,6\% dipengaruhi faktor lain. Uji hipotesis diperoleh nilai $\mathrm{F}$ hitung $>\mathrm{F}$ tabel atau $(56,216>$ $3,970)$.

\section{Saran}

a. Pelatihan pernyataan yang paling lemah adalah nomor 3 yaitu Pelatihan yang diikuti sudah sesuai dengan kebutuhan kompetensi pegawai, dimana hanya mencapai rata-rata score sebesar 3,74. Untuk lebih baik lagi lembaga harus menyelarskan pelatihan yang diadakan harus sesuai dengan kebutuhan pegawainya sehingga mampu menunjang pekerjaan.

b. Motivasi pernyataan yang paling lemah adalah nomor 7 yaitu Pimpinan memberikan arahan terkait job description tugas bawahan, dimana hanya mencapai rata-rata score sebesar 3,65. Untuk lebih baik lagi lembaga harus membuat uraian tugas dan kewajiban pegawainya sehingga pegawai mampu mengimplementasikan tugas tersebut dalam pekerjaannya

c. Kinerja pegawai pernyataan yang paling lemah adalah nomor 7 yaitu Pegawai mampu bekerjasama antar departemen dengan baik, dimana hanya mencapai rata-rata score sebesar 3,64. Untuk lebih baik lagi lembaga harus mendorong masing-masing unit kerja mampu bekerja secata tim.

\section{DAFTAR PUSTAKA}

A.A. Anwar Prabu Mangkunegara (2015), Manajamen Sumber Daya Manusia Perusahaan, PT Remaja Rosdakarya, Bandung.

Algifari (2015). Analisis Regresi untuk Bisnis dan Ekonomi. Yogyakarta: BPFE.

D Sunarsi. (2020). Kepemimpinan Bisnis Strategik. Kota Serang: Desanta Muliavisitama

Dharma,Surya (2013), Manajemen Kinerja, Falsafah Teori \& Penerapannya, Pustaka Pelajar, Yogyakarta.

Handoko T. Hani, (2017), Manajemen Personalia dan Sumber Daya Manusia, edisi kedua, BPFE, Yogyakarta.

Hasibuan, Malayu SP (2016), Manajemen Sumber Daya Manusia, Edisi Revisi, Penerbit Bumi Aksara, Jakarta.

Henry Simamora (2015), Manajemen Sumber Daya Manusia, STIE YKPN Bandung. Imam Ghozali (2017). Aplikasi Analisis Multivariate Dengan Program SPSS. Edisi Kelima. Semarang: Badan Penerbit Undip.

Istijanto (2014) Riset Sumber Daya Manusia. Jakarta: PT. Gramedia Pustaka

Lukiastuti, Fitri, et.al (2020). The Influence of Entrepreneur's Personal Characteristics on

SMES Performance Mediated by Entrepreneurial Orientation. International Journal of

Psychosocial Rehabilitation. Volume 24 - Issue 8

Sedarmayanti (2015), Sumber Daya Manusia dan Produktivitas Kerja, CV. Mandar Maju, Bandung.

Singgih Santoso (2015). Menguasai Statistik Multivariat. Jakarta: PT Elex Media Komputindo. 
Sondang, P.Siagian ( 2015), Manajemen Sumber Daya Manusia, Bumi Aksara, Jakarta Sudjana (2014) Metode Statistika, Bandung: Tarsido.

Sugiyono (2017), Metode Penelitian Administrasi : dilengkapi dengan Metode $R \& D$, Bandung: Alfabeta.

Sunarsi, D. (2018). Buku Ajar: Seminar Perencanaan Sumber Daya Manusia. Tangerang Selatan: Asmoro Mediatama

Sunarsi, D. (2018). Pengembangan Sumber Daya Manusia Strategik \& Karakterisrik Sistem Pendukungnya : Sebuah Tinjauan. Jurnal Ilmiah MEA (Manajemen, Ekonomi, \& Akuntansi), 2(3), 178 - 194.

Sunarsi, D. (2019). Seminar Sumber Daya Manusia. Tangerang Selatan: Unpam Press

Sutrisno, S., \& Sunarsi, D. (2019). The Effect of Work Motivation and Discipline on Employee Productivity at PT. Anugerah Agung in Jakarta. Jurnal Ad'ministrare, 6(2), 187-196.

Sutrisno, Edy. 2016. Manajemen Sumber Daya Manusia. Yogyakarta: Kencana Prenada Media 